\title{
Topology Optimization using an Explicit Interface Representation
}

Christiansen, Asger Nyman; Nobel-Jørgensen, Morten; Bærentzen, J. Andreas; Aage, Niels; Sigmund, Ole

Publication date:

2013

Link back to DTU Orbit

Citation $(A P A)$ :

Christiansen, A. N., Nobel-Jørgensen, M., Bærentzen, J. A., Aage, N., \& Sigmund, O. (2013). Topology Optimization using an Explicit Interface Representation. Abstract from 10th World Congress on Structural and Multidisciplinary Optimization, Orlando, FL, United States.

\section{General rights}

Copyright and moral rights for the publications made accessible in the public portal are retained by the authors and/or other copyright owners and it is a condition of accessing publications that users recognise and abide by the legal requirements associated with these rights.

- Users may download and print one copy of any publication from the public portal for the purpose of private study or research.

- You may not further distribute the material or use it for any profit-making activity or commercial gain

- You may freely distribute the URL identifying the publication in the public portal

If you believe that this document breaches copyright please contact us providing details, and we will remove access to the work immediately and investigate your claim 


\title{
Topology Optimization using an Explicit Interface Representation
}

\author{
Asger Nyman Christiansen, Morten Nobel-Jørgensen, Jakob Andreas Bærentzen \\ Department of Applied Mathematics and Computer Science, Technical University of Denmark, \\ Asmussens Allé, B.305, 2800 Kgs. Lyngby, Denmark, e-mail: asny@dtu.dk
}

\section{Niels Aage, Ole Sigmund}

Department of Mechanical Engineering, Technical University of Denmark, Nils Koppels Allé, B.404, 2800 Kgs. Lyngby, Denmark

Current methods for topology optimization primarily represent the interface between solid and void implicitly on fixed grids. In contrast, shape optimization methods represent the interface explicitly, but do not allow for any topological changes to the structure. Using an explicit interface representation has a number of advantages as described below. Consequently, we propose to use the Deformable Simplicial Complex (DSC) method [1] which represents the interface explicitly as one or more closed piecewise linear curves in $2 \mathrm{D}$.

As opposed to pure shape optimization methods, the DSC method is able to handle topology changes. It does so by discretizing the entire design domain into an irregular adaptive triangle mesh and thereby explicitly representing both the structure and the embedding space. In other words, the entire design domain is divided into triangles, where the interface is represented as piecewise linear curves between void and non-void triangles.

Another advantage of the DSC method is that we can exploit the triangle mesh for the FEM computations used in the optimization procedure. The non-void elements define the structure and their deformation is described by second order shape functions. To increase performance, degrees of freedom associated with void triangles are eliminated from the FE equation. Using the triangle mesh for computations is possible since the DSC method ensures a mesh with no degenerate elements. If the mesh contained degenerate or close to degenerate elements the FEM computations would break down and the results would no longer be valid. The DSC method solves this issue by a series of mesh operations which keeps the mesh ever well-formed. Put another way, the consequence of using a well-formed adaptive mesh is that the representation for the FEM calculations and the shape of the structure can be one and the same.

In addition to unifying calculations and representation of the structure, the approach also unifies shape and topology optimization into a single framework. Furthermore, it combines the two in a simultaneous optimization strategy. Here, the shape is optimized on the basis of the gradient based optimization algorithm Method of Moving Asymptotes whereas holes are introduced using topological derivatives. Since we combine these methods, and since FEM calculations are performed only on non-void triangles and gradients are calculated only for the interface nodes, the presented approach is efficient.

An explicit representation is not just useful when considering simplicity and performance. In many cases, the explicitly represented interface is necessary to be able to model a problem. For example for flow or electromagnetic problems with localized boundary effects. Furthermore, control of boundary smoothness is simple to implement and can e.g. be used to control fillet radius at corners. The method also opens up for the opportunity to apply other local constraints, such as min/max length scale of the structure. Finally, the explicit interface is in all cases necessary when interpreting the final design.

The status of the work is that the method has been developed and is showing promising results. For instance, the cantilever beam problem has been solved to a high precision using a fine discretization by evaluating the objective function approximately 500 times. This took around 100 seconds on an ordinary laptop utilizing a single thread. In addition, a coarse solution to the same problem has been obtained in approximately 10 seconds.

\section{References}

[1] Marek Krzysztof Misztal and Jakob Andreas Bærentzen. Topology adaptive interface tracking using the deformable simplicial complex. ACM Transactions on Graphics, 31(3):No. 24, 2012. 